\title{
Üç Farklı Bölgeye Ait Pomzanın Yüksek Plastisiteli Kile Etkisinin Karşılaştırılması
}

\author{
Ömür ÇİMEN ${ }^{*}$, Burak DERELİ², Erhan KELEŞ ${ }^{3}$ \\ ${ }^{I}$ Süleyman Demirel Üniversitesi, Mühendislik Fakültesi, İnşaat Mühendisliği Bölümü, Isparta \\ ${ }^{2}$ Bitlis Eren üniversitesi, Tatvan Meslek Yüksekokulu, İnşaat Bölümü, Bitlis \\ ${ }^{3}$ Süleyman Demirel Üniversitesi, Mühendislik Fakültesi, İnşaat Mühendisliği Bölümü (YL), Isparta \\ (ORCID: 0000-0002-6138-6029) (ORCID: 0000-0003-4062-0792) (ORCID: 0000-0001-8712-5540)
}

\begin{abstract}
$\ddot{O} \mathbf{z}$
Yapı temelleri altında taşıyıcı tabaka olarak kullanılan zemin, her zaman istenilen özelliklere sahip olmayabilir. Böyle durumlarda, inşaat yerinin değiştirilmesi, istenilen özelliklere sahip olmayan tabakaların kaldırılarak uygun zeminlerin yerleştirilmesi gibi çözümler genelde ekonomik değildir. İstenilen özelliklere sahip olmayan zeminler, farklı katkı maddeleri kullanılarak yerinde iyileştirme ile daha ekonomik çözümler sunabilir. Pomza patlamalı volkanizma sonucunda oluşmuş, boşluklu, süngerimsi bir kayaç olup, patlamalı volkanik faaliyetlerin bulunduğu dünyanın birçok bölgesinde bulunur. Özellikle ülkemiz pomza rezervi açısından iyi bir potansiyele sahiptir. Bu çalışmada Bitlis, Manisa Kula ve Isparta bölgesine ait pomzaların yüksek plastisiteli kile etkisi araştırılmış ve karşılaştırılmıştır. Kile $\% 10, \% 20, \% 30$ oranlarında Isparta Gelincik ve Bitlis pomzası, \%10, \%20, \%25 oranlarında Manisa Kula pomzası ilave edilerek pomza-kil ikili karışımları hazırlanmıştır. Kireç (\%6) sabit tutularak \%10, \%20, \%30 oranlarında Isparta Gelincik ve Bitlis pomzası, kireç (\%5) sabit tutularak \%10, \%20, $\% 25$ oranlarında Manisa Kula pomzası ilave edilerek pomza-kil-kireç üçlü karışımlar hazırlanmıştır. Bu karışımlar kullanılarak kompaksiyon, kıvam limitleri, serbest basınç ve şişme deneyleri yapılmış̧ır. Pomza-kil ikili karışımlarda ideal pomza oranları Isparta Gelincik, Manisa Kula ve Bitlis pomzaları için sırasıyla \%30, \%20, \%20 olarak belirlenmiştir. Pomza-kil-kireç üçlü karışımlarında ise Isparta Gelincik pomzası için ideal oranın olmadığı, Manisa Kula pomzası için $\% 25$ ve Bitlis pomzası için \%10 olarak belirlenmiştir.
\end{abstract}

Anahtar kelimeler: Zemin stabilizasyonu, pomza, kireç, yüksek plastisiteli kil.

\section{Comparison of The Effect of Pumice of Three Different Regions to High Plasticity Clay}

\begin{abstract}
The soil used as a bearing layer under construction foundations may not always have the desired properties. In such cases, solutions such as replacing the construction site and removing the layers that do not have the desired properties by placing suitable floors are generally uneconomical. Soils that do not have the desired properties can offer more economical solutions with insitu improvement by using different additives. The pumice is a spongy, porous, and volcanic rock. It is possible to find this rock formation in many regions of the world where volcanic activities are exist. Especially our country has a good potential in terms of pumice reserve. In this study, the effect of pumice of Bitlis, Manisa - Kula and Isparta regions on high plasticity clay was investigated and compared. Pumice-clay binary mixtures were prepared by adding 10\%, 20\%, 30\% to clay, Isparta Gelincik and Bitlis pumice, $10 \%, 20 \%, 25 \%$ Manisa Kula pumice. The lime (6\%) is kept constant 10\%, 20\%, 30\% of Isparta Gelincik and Bitlis pumice, lime (5\%) is kept constant 10\%, 20\%, 25\% Manisa Kula pumice by adding pumice-clay-lime triple mixtures prepared. Compaction, consistency limits, free pressure and swelling tests were performed using these mixtures. The ideal pumice ratios in pumice-clay double mixtures were determined as 30\%, 20\%, 20\% for Isparta Gelincik, Manisa Kula and Bitlis pumice respectively. In pumice-clay-lime triple mixtures, there was no ideal ratio for Isparta Gelincik pumice, 25\% for Manisa Kula pumice and 10\% for Bitlis pumice.
\end{abstract}

Keywords: Soil stabilization, pumice, lime, high plasticity clay.

*Sorumlu yazar: omurcimen@sdu.edu.tr

Geliş Tarihi:28.05.2019, Kabul Tarihi: 18.10.2019 


\section{Giriş}

Stabilizasyon, mühendislik yapıları için istenilen özeliklere sahip olmayan zemin yapısının kimyasal, mekanik ve fiziksel iyileştirme yöntemleri ile dış kuvvetlere karşı dayanıklı hale getirilmesidir [1]. Zemin bina, baraj, yol ve köprü gibi her türlü mühendislik yapılarının üzerine inşa edildiği, bu şekilde yapıların yükünü taşıyan, daneli yapıya sahiptir. Zeminler, çeşitli kayaçların farklı dış kuvvetler etkisiyle ayrışması sonucu oluşan taneli ve boşluklu bir yığındır. Daneler, hareketli yükler, sabit yükler ve yer çekimi etkisi ile birbiri üzerinde durur. Danelerden oluşan zemin iskeleti, daneler arası sürtünme dayanımı ile mekanik dirençlere kuvvet gösterir. Zemin daneleri arasındaki bu direnç mukavemeti gelen yükleri taşıyamadığında çeşitli zemin iyileştirme yöntemlerine başvurulur. Genelde yol, hava alanı ve toprak baraj inşaatlarında karşılaşılan bu problemlerden zemin iyileştirme yapılarak kurtulmak mümkündür [2].

Kil hidratlı alüminyum ve magnezyum silikatlardan oluşan ikincil bir mineraldir. Dane boyutu 2 mikrondan daha küçük olup aynı boyuttaki diğer minerallerden farkı, su ile karıştırıldığında çamur haline gelmesidir. Killer genellikle kurutulduğunda hacmi azalır ve çatlar; 1slatıldığında ise hacim artış1 meydana gelir. Toprakların mineral içeriği çoğunlukta kuvars olan çakıl, kum, silt ve ikincil silikatlardan oluşmuş kil olarak gösterilirse, diğer bileşenlerin toplamının \% 25'i geçmediği karışımlar da killi zemin olarak adlandırılır. Kil mühendislik, tarım, ormancılık, seramik endüstrisi ve tıpta önemli bir endüstriyel gereçtir. Killer yararlı özelliklerinden dolayı çoğu kez geoteknik mühendisliği tarafindan aranan bir mineraldir. Göletlerin su tutması, atık depolarında ve dolgu barajlarda geçirimsizliğin sağlanması için etkin kullanılan bir malzemedir [3]. Kil zeminler, genel olarak su muhtevasındaki değişimi takiben hacim değişimine uğrarlar. Zemin numunesinin kuruduğunda, büzülmesi 1slatıldığında ise şişmesi, hacim değişimi olarak tanımlanır. Büyük hacimsel değişiklikler çok değişken iklim şartlarında meydana gelir. Killerin oturma, mukavemet, şişme ve büzülme özelikleri mühendislik yapılarını ciddi anlamda negatif yönde etkilemektedir.

Karthik vd. (2014), yaptıkları çalışmada kile $\% 0, \% 3, \% 5, \% 6$ ve $\% 9$ oranlarında uçucu kül ilave ederek CBR ve diğer dayanım özellik testleri yapmışlardır. Uçucu kül oranının artmasına bağlı olarak maksimum kuru birim hacim ağırlığının ve CBR yüzdesinin arttığını, plastik limit ve likit limit değerinin azaldığını tespit etmişlerdir [4].

Taş vd. (2018), çalışmalarında zemin stabilizasyonu için uçucu kül ve Bayburt taşı endüstriyel atıkları kullanmışlardır. Çalışma kapsamında düşük plastisiteli killi bir zeminin stabilizasyonunda kullanılan $\% 25$ uçucu küle, $\% 0, \% 5, \% 10, \% 15, \% 20$ oranlarında Bayburt taşı ilave etmişlerdir. Hazırlanan karışımların indeks ve dayanım gibi geoteknik özelliklerini araştırmışlardır. Tek eksenli serbest basınç dayanımı değerlerine göre Bayburt taşının \%10 oranında katıldığı $\% 25$ uçucu kül içeren karışımın en yüksek dayanım değerini verdiğini belirlemişlerdir[5].

$\mathrm{Bu}$ çalışmada üç farklı bölgeye ait pomzanın, yüksek plastisiteli kile olan etkisi araştırılıp, deney sonuçları karşılaştırılmıştır.

\section{Materyal ve Metot}

\subsection{Kullanılan Malzemelerin Tanıtılması}

Patlamalı volkanik faaliyetlerin bulunduğu dünyanın birçok yerinde bulunan pomza taşı oluşumları, volkanik püskürmeler sonucu oluşmuş boşluklu ve süngerimsi bir kayaçtır. Bu taş oluşumları, ekonomik değerliliği bakımından dünyada önemli bir yere sahip olup, ülkemizde hatırı sayılır bir rezerve sahiptir. Pomza taşı rezervleri bakımından Kayseri, Nevşehir, Niğde, Bitlis ve Van illerimiz önemli bir konuma sahiptir[6].

Pomza, asidik (Şekil 1a) ve bazik pomza (Şekil 1b) olmak üzere iki kısma ayrılır. Asidik pomza beyaz ve kirli beyaz renktedir ve Mohs skalasına göre sertliği 5-6 olup, yoğunluğu $0.5-1 \mathrm{gr} / \mathrm{cm}^{3}$ 'tür. Bazik pomza ise kahve renkli veya siyah olup daha ağırdır ve Mohs sertliği 5-6 olup, yoğunluğu ise 1$2 \mathrm{gr} / \mathrm{cm}^{3}$ 'tür. Asidik ve bazik pomzaların genel kimyasal özellikleri Tablo 1'de verilmiştir. Bu çalışmada üç farklı bölgenin (Isparta - Gelincik, Manisa - Kula ve Bitlis) pomzası kullanılmıştır. Bu pomzalara ait kimyasal analiz sonuçları Tablo 2 'de gösterilmiştir. 


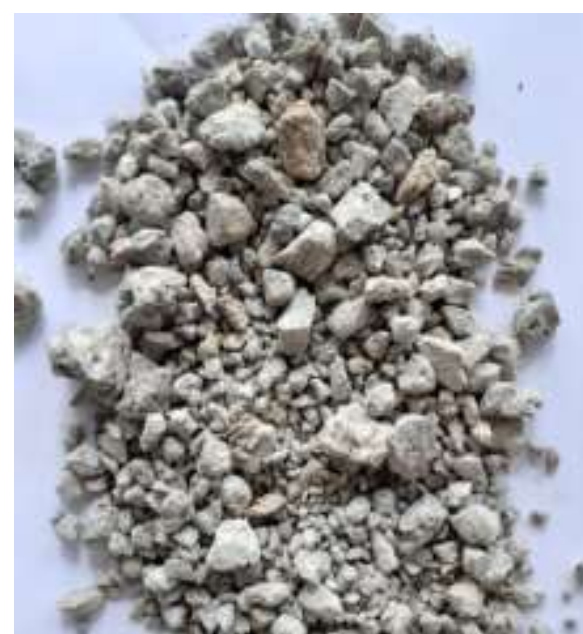

(a)

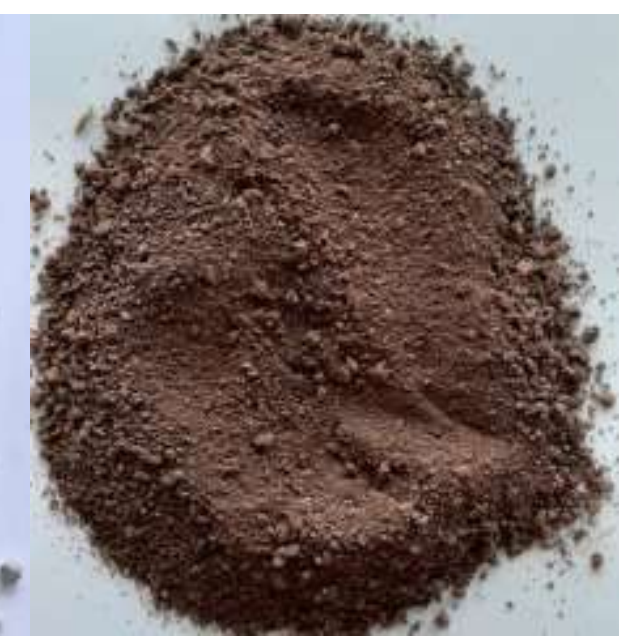

(b)

Şekil 1. Asidik ve bazik pomza

Tablo 1. Asidik ve bazik pomzaların genel kimyasal özellikleri [7]

\begin{tabular}{ccc}
\hline Oksitler & Asidik Pomza (\%) & Bazik Pomza (\%) \\
$\mathrm{SiO}_{2}$ & 70 & 45 \\
$\mathrm{Al}_{2} \mathrm{O}_{3}$ & 14 & 21 \\
$\mathrm{Fe}_{2} \mathrm{O}_{3}$ & 2.5 & 7 \\
$\mathrm{CaO}$ & 0.9 & 11 \\
$\mathrm{Na}_{2} \mathrm{O}+\mathrm{K}_{2} \mathrm{O}$ & 9 & 8 \\
$\mathrm{MgO}$ & 0.6 & 7 \\
Kizdirma Kaybi (K.K) & 3 & 1 \\
\hline
\end{tabular}

Tablo 2. Üç bölgeye ait pomzanın kimyasal özellikleri [8-10]

\begin{tabular}{cccc}
\hline Oksitler & Isparta Gelincik (\%) & Manisa Kula (\%) & Bitlis (\%) \\
\hline $\mathrm{Na}_{2} \mathrm{O}$ & 5.3 & 1.08 & 5.25 \\
$\mathrm{MgO}$ & 1.1 & --- & 0.14 \\
$\mathrm{Al}_{2} \mathrm{O}_{3}$ & 17.1 & 2.60 & 13.12 \\
$\mathrm{SiO}_{2}$ & 60.9 & 92.48 & 68.08 \\
$\mathrm{P}_{2} \mathrm{O}_{5}$ & 0.2 & --- & --- \\
$\mathrm{K}_{2} \mathrm{O}$ & 5.0 & 0.04 & --- \\
$\mathrm{CaO}$ & 3.0 & 0.31 & 0.71 \\
$\mathrm{TiO}_{2}$ & 0.3 & 1.34 & --- \\
$\mathrm{MnO}_{\mathrm{Fe}_{2} \mathrm{O}_{3}}$ & 0.1 & --- & --- \\
$\mathrm{K}_{12 d 1 r m a ~ K a y b}$ & 3.2 & 0.09 & 4.47 \\
\hline
\end{tabular}

Kireç, doğal kireçtaşından üretilir. Kireçtaşı, sedimanter bir kayaç olup yüksek kalsiyumlu, magnezyumlu veya dolomitik yapıda olabilir. Kireç taşının yapısına ve üretim aşamalarına bağlı olarak farklı özelliklerde kireçlerin öretilmesi mümkündür. Yüksek kalsiyumlu sönmemiş kireç $(\mathrm{CaO})$, monohidrate dolomitik kireç $\left(\mathrm{Ca}(\mathrm{OH})_{2} \mathrm{MgO}\right)$ ve yüksek kalsiyumlu sönmüş kireç $\left(\mathrm{Ca}(\mathrm{OH})_{2}\right)$ zemin iyileştirmede en çok kullanılan kireç türleridir [8]. Bu çalışmada sönmemiş yüksek kalsiyumlu kireç kullanılmıştır. Kullanılan kirecin kimyasal özellikleri Tablo 3 'te verilmiştir.

Tablo 1. Kirecin kimyasal özellikleri [8].

\begin{tabular}{llllllllllll}
\hline Oksit & $\mathrm{Al}_{2} \mathrm{O}_{3}$ & $\mathrm{Fe}_{2} \mathrm{O}_{3}$ & $\mathrm{CaO}$ & $\mathrm{Na}_{2} \mathrm{O}$ & $\mathrm{MgO}$ & $\mathrm{K}_{2} \mathrm{O}$ & $\mathrm{TiO}_{2}$ & $\mathrm{SiO}_{2}$ & $\mathrm{MnO}$ & $\mathrm{P}_{2} \mathrm{O}_{5}$ & $\mathrm{~K} . \mathrm{K}$. \\
\hline$\%$ & $<0.1$ & 0.1 & 79.3 & $<0.1$ & 0.4 & $<0.1$ & $<0.1$ & 0.1 & $<0.1$ & $<0.1$ & 19.85 \\
\hline
\end{tabular}

Bu çalışmada Muğla'nın Fethiye ilçesinde yapılan Eşen barajlarında şantiye sahasından alınan kil numunesi ile çalışılmıştır. Kilde simektik grubu mineral, serpantin grubu mineral, kuvars, kalsit, amorf silika, amfibol grubu mineral (çok az), klorit grubu mineral (çok az) bulunmaktadır[8]. Kilin kimyasal özellikleri Tablo 4 'te verilmiştir. 
Tablo 2. Kilin kimyasal özellikleri [8].

\begin{tabular}{llllllllllll}
\hline Oksit & $\mathrm{Na}_{2} \mathrm{O}$ & $\mathrm{MgO}$ & $\mathrm{Al}_{2} \mathrm{O}$ & $\mathrm{SiO}_{2}$ & $\mathrm{P}_{2} \mathrm{O}_{5}$ & $\mathrm{~K}_{2} \mathrm{O}$ & $\mathrm{CaO}$ & $\mathrm{TiO}_{2}$ & $\mathrm{MnO}$ & $\mathrm{Fe}_{2} \mathrm{O}_{3}$ & K.K. \\
\hline$\%$ & $<0.1$ & 17.4 & 4.3 & 47.1 & $<0.1$ & 0.3 & 2.8 & 0.2 & 0.1 & 16.6 & 9.85 \\
\hline
\end{tabular}

\subsection{Araştırma Kapsamında Yapılan Deneyler}

Kilin kıvam limitlerine, kompaksiyon parametrelerine, serbest basınç direncine ve şişme basıncına pomzanın ve kirecin etkilerinin belirlenmesi amacıyla, kile belirli oranlarda pomza ve kireç ilave edilmiştir. Pomza-kil ikili karışımlarında $\% 10, \% 20, \% 30$, ağırlık oranlarında pomza kullanılmıştır. Pomza-kil-kireç üçlü karışımlarında kireç oranı \%6 'da sabit tutularak \%10, \%20, \%30 ağırlık oranlarında pomza ilave edilir. İkili karışım olarak adlandırılan pomza-kil deneylerinin tamamlanmasının ardından üçlü karışım pomza-kil-kireç deneyleri yapılmıştır.

Kıvam limitleri olarak bilinen likit ve plastik limitin belirlenmesinde [11] deney metodu kullanılmıştır. Pomza ve kireç, No 40 elekten elenerek, yukarıda belirtilen miktarlarda yine No 40 elekten elenen kile eklenmiştir. Numunelerin kompaksiyon özelliklerinin belirlenmesi için [12] standartlarındaki standart kompaksiyon deneyi yapılmıştır. Her bir karışım oranı için standart kompaksiyon deneylerinden elde edilen maksimum kuru birim hacim ağırlığı ve optimum su muhtevası verilerinden yararlanılarak hazırlanan numuneler üzerinde serbest basınç deneyleri yapılmıştır. [13] standartlarında yapılan serbest basınç deneylerinde No 40 elek altına geçen numuneler kullanılmıştır. Serbest basınç numuneleri $3.8 \mathrm{~cm}$ çapında ve $7.6 \mathrm{~cm}$ yüksekliğinde ikiye ayrılabilen ringe tabakalar halinde serilerek sıkıştırılmıştır. Ringden çıkarılan numuneler üzerinde $0.5 \mathrm{~mm} / \mathrm{dk}$ yükleme hızıyla yükleme yapılarak serbest basınç deneyleri yapılmıştır. İncelenen zemin numunelerinin şişme basınçları, sabit hacim ödometre deney yöntemi [14] metot C kullanılarak belirlenmiştir.

\section{Bulgular ve Tartışma}

Kil üzerinde yapılan elek ve hidrometre analizinde numunenin içerisinde $\% 0$ çakı1, $\% 2$ kum, \%38 silt ve \%60 kil olduğu belirlenmiştir. Birleştirilmiş Zemin Sınıflandırma Sistemine göre, zeminin CH (Yüksek plastisiteli kil) sınıfında olduğu tespit edilmiştir[8]. Kil numunesinin dane birim hacim ağırlı̆̆ $2.7 \mathrm{~g} / \mathrm{cm}^{3}$ tür. Numune üzerinde kıvam limitleri, standart kompaksiyon, serbest basınç ve şişme deneyleri yapılarak sonuçlar Tablo 5-7'de verilmiştir.

Üç farklı pomza üzerinde piknometre deneyleri yapılmış olup sırasıyla dane birim hacim ağırlıkları Isparta Gelincik pomzası için $2.42 \mathrm{gr} / \mathrm{cm}^{3}$, Manisa Kula pomzası için $2.64 \mathrm{gr} / \mathrm{cm}^{3}$, Bitlis pomzası için $2.41 \mathrm{gr} / \mathrm{cm}^{3}$ olarak bulunmuştur. Ayrıca, numuneler üzerinde standart kompaksiyon deneyleri yapılmış, deney sonuçları Şekil 2'de verilmiştir.

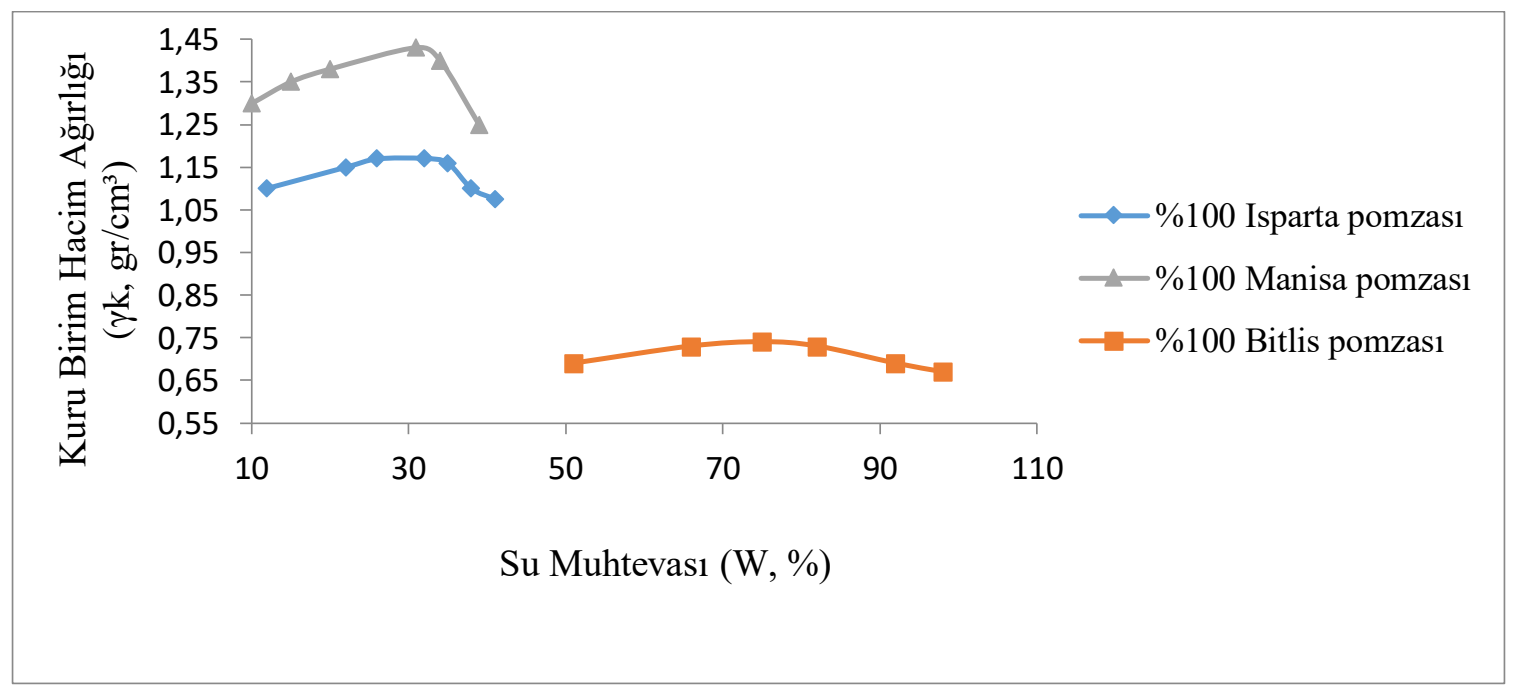

Şekil 2. Üç farklı bölgeye ait pomzanın standart kompaksiyon eğrileri. 
Kompaksiyon sonuçlarına göre Isparta Gelincik ve Manisa Kula pomzalarının optimum su muhtevası birbirine yakın iken Bitlis pomzasında optimum su muhtevasının bunlardan çok yüksek, kuru birim hacim ağırlığının ise çok düşük olduğu tespit edilmiştir.

Tablo 3. Isparta Gelincik pomzası katkılı kilin deney sonuçları[8].

\begin{tabular}{|c|c|c|c|c|c|c|c|}
\hline Numuneler & $\begin{array}{l}\text { WL } \\
(\%)\end{array}$ & $\begin{array}{l}\text { WP } \\
(\%)\end{array}$ & $\begin{array}{c}\text { PI } \\
(\%)\end{array}$ & $\begin{array}{c}\gamma_{\mathrm{kmax}} \\
\left(\mathrm{g} / \mathrm{cm}^{3}\right)\end{array}$ & $\begin{array}{l}\mathrm{W}_{\mathrm{opt}} \\
(\%)\end{array}$ & $\begin{array}{c}\mathrm{qu}_{\mathrm{u}} \\
\left(\mathrm{kg} / \mathrm{cm}^{2}\right)\end{array}$ & $\begin{array}{c}\text { Ps }\left(\mathrm{kg} / \mathrm{cm}^{2}\right) \\
\text { (Serbest } \\
\text { şişme) }\end{array}$ \\
\hline$\% 100 \mathrm{Kil}$ & 108 & 38 & 70 & 1.16 & 38 & 1.96 & 1.60 \\
\hline$\% 100 \mathrm{P}_{\mathrm{I}}$ & --- & --- & --- & 1.18 & 29 & 0.45 & --- \\
\hline$\% 10 \mathrm{P}_{\mathrm{I}}+\% 90 \mathrm{Kil}$ & 95 & 32.5 & 62.5 & 1.16 & 29 & 2.95 & 0.40 \\
\hline$\% 20 \mathrm{P}_{\mathrm{I}}+\% 80 \mathrm{Kil}$ & 89 & 27 & 62 & 1.23 & 35 & 4.29 & 0.37 \\
\hline$\% 30 \mathrm{P}_{\mathrm{I}}+\% 70 \mathrm{Kil}$ & 80 & 27 & 53 & 1.30 & 32 & 5.50 & 0.25 \\
\hline$\% 10 \mathrm{P}_{\mathrm{I}}+\% 6 \mathrm{~K}+\% 84 \mathrm{Kil}$ & 85 & 64 & 21 & 1.31 & 26 & 3.52 & 0.81 \\
\hline$\% 20 \mathrm{P}_{\mathrm{I}}+\% 6 \mathrm{~K}+\% 74 \mathrm{Kil}$ & 75 & 63 & 15 & 1.31 & 24 & 3.84 & 0.49 \\
\hline$\% 30 \mathrm{P}_{\mathrm{I}}+\% 6 \mathrm{~K}+\% 64 \mathrm{Kil}$ & 65 & --- & --- & 1.28 & 26 & 3.39 & 0.02 \\
\hline
\end{tabular}

Tablo 5'de $\mathrm{P}_{\mathrm{I}}$; Isparta Gelincik pomzasın1, K; Kireci, WL; Likit limiti, WP; Plastik limiti, PI; Plastisite indisini, $\gamma_{\text {kmax }}$; Maksimum kuru birim hacim ağırlığını, $\mathrm{W}_{\mathrm{opt}}$; Optimum su muhtevasını, $\mathrm{q}_{\mathrm{u}}$; Serbest basınç direncini, Ps; Şişme basıncını göstermektedir.

Tablo 4. Manisa Kula pomzası katkılı kilin deney sonuçları[9].

\begin{tabular}{llllllll}
\hline Numuneler & $\begin{array}{l}\mathrm{WL} \\
(\%)\end{array}$ & $\begin{array}{l}\text { WP } \\
(\%)\end{array}$ & $\begin{array}{l}\text { PI } \\
(\%)\end{array}$ & $\begin{array}{l}\gamma_{\mathrm{kmax}} \\
\left(\mathrm{g} / \mathrm{cm}^{3}\right)\end{array}$ & $\begin{array}{l}\mathrm{W}_{\text {opt }} \\
(\%)\end{array}$ & $\begin{array}{l}\mathrm{q}_{\mathrm{u}} \\
\left(\mathrm{kg} / \mathrm{cm}^{2}\right)\end{array}$ & $\begin{array}{l}\mathrm{Ps}\left(\mathrm{kg} / \mathrm{cm}^{2}\right) \\
(\text { Sabit şişme })\end{array}$ \\
\hline$\% 100 \mathrm{P}_{\mathrm{M}}$ & --- & --- & --- & 1.44 & 23 & 0.38 & 0.003 \\
$\% 10 \mathrm{P}_{\mathrm{M}}+\%$ \% Kil & 94 & 35 & 59 & 1.16 & 46 & 1.36 & 0.380 \\
$\% 20 \mathrm{P}_{\mathrm{M}}+\%$ 8Kil & 83 & 35 & 48 & 1.28 & 32 & 2.55 & 0.240 \\
$\% 25 \mathrm{P}_{\mathrm{M}}+\% 75 \mathrm{Kil}$ & 80 & 38 & 42 & 1.33 & 36 & 2.20 & 0.093 \\
$\% 10 \mathrm{P}_{\mathrm{M}}+\% 5 \mathrm{~K}+\% 85 \mathrm{Kil}$ & 95 & 62 & 33 & 1.26 & 36 & 5.20 & 0.110 \\
$\% 20 \mathrm{P}_{\mathrm{M}}+\%$ K+\%75Kil & 66 & 50 & 16 & 1.28 & 31 & 5.40 & 0.032 \\
$\% 25 \mathrm{P}_{\mathrm{M}}+\% 5 \mathrm{~K}+\% 65 \mathrm{Kil}$ & 66 & 50 & 16 & 1.36 & 24 & 7.00 & 0.029 \\
\hline
\end{tabular}

Tablo 6'da $\mathrm{P}_{\mathrm{M}}$; Manisa Kula pomzasını göstermektedir.

Tablo 5. Bitlis pomzası katkılı kilin deney sonuçları.

\begin{tabular}{llllllll}
\hline Numuneler & $\begin{array}{l}\text { WL } \\
(\%)\end{array}$ & $\begin{array}{l}\text { WP } \\
(\%)\end{array}$ & $\begin{array}{l}\text { PI } \\
(\%)\end{array}$ & $\begin{array}{l}\gamma_{\mathrm{kmax}} \\
\left(\mathrm{g} / \mathrm{cm}^{3}\right)\end{array}$ & $\begin{array}{l}\mathrm{W}_{\text {opt }} \\
(\%)\end{array}$ & $\begin{array}{l}\mathrm{q}_{\mathrm{u}} \\
\left(\mathrm{kg} / \mathrm{cm}^{2}\right)\end{array}$ & $\begin{array}{l}\mathrm{Ps}\left(\mathrm{kg} / \mathrm{cm}^{2}\right) \\
(\text { Sabit şişme })\end{array}$ \\
\hline$\% 100 \mathrm{P}_{\mathrm{B}}$ & --- & --- & --- & 0.74 & 75 & 0.74 & ---- \\
$\% 10 \mathrm{P}_{\mathrm{B}}+\% 90 \mathrm{Kil}$ & 98.75 & 31 & 67.75 & 1.21 & 37 & 3.34 & 1.53 \\
$\% 20 \mathrm{P}_{\mathrm{B}}+\% 80 \mathrm{Kil}$ & 96.88 & 29.5 & 67.38 & 1.125 & 32 & 5.36 & 0.26 \\
$\% 30 \mathrm{P}_{\mathrm{B}}+\% 70 \mathrm{Kil}$ & 87.95 & 28.5 & 59.45 & 1.12 & 35 & 3.003 & 0.31 \\
$\% 10 \mathrm{P}_{\mathrm{B}}+\% 6 \mathrm{~K}+\% 84 \mathrm{Kil}$ & 86.01 & 56 & 30.01 & 1.2 & 28 & 15.64 & 0.33 \\
$\% 20 \mathrm{P}_{\mathrm{B}}+\% 6 \mathrm{~K}+\% 74 \mathrm{Kil}$ & 86.14 & 52 & 34.14 & 1.125 & 35 & 7.89 & 0.041 \\
$\% 30 \mathrm{P}_{\mathrm{B}}+\% 6 \mathrm{~K}+\% 64 \mathrm{Kil}$ & 85.85 & 51.5 & 34.35 & 1.042 & 34 & 7.24 & 0.048 \\
\hline
\end{tabular}

Tablo 7'de $\mathrm{P}_{\mathrm{B}}$; Bitlis pomzasını göstermektedir.

\section{Sonuç ve Öneriler}

Isparta Gelincik pomzasının kile ilave edilmesi ile pomza-kil ikili karışımlarda, pomza miktarının artması ile likit limit, plastik limit, optimum su muhtevası ve şişme basıncının azaldığı, maksimum kuru birim hacim ağırlığın ve serbest basınç direncinin ise artığı görülmüştür. Pomza-kil-kireç üçlü karışımlarında ise pomza oranının artması ile likit limit, plastisite indisi, optimum su muhtevası ve şişme basıncının azaldığı, plastik limit ve serbest basınç direncinin ise arttığı görülmüştür. Pomza-kil ikili karışımları için ideal pomza karışım oranı \%30 olarak belirlenmiştir. Pomza-kil-kireç üçlü 
karışımlarında ise serbest basınç mukavemeti açısından ikili karışımlarla kıyaslandığında daha ideal oran görülmemiştir.

Manisa Kula pomzasının kile ilave edilmesi ile pomza-kil ikili karışımlarında pomza oranının artması ile likit limit, plastik limit, plastisite indisi ve şişme basıncının azaldığ 1 \% $\% 10$ pomza oranında optimum su muhtevasının artığı, \%20 ve \%25 pomza oranında ise optimum su muhtevasının azaldığı, kuru birim hacim ağırlığın ve serbest basınç direncinin ise arttı̆̆ görülmüştür. Pomza-kil-kireç üçlü karışımlarda ise pomza oranının artması ile likit limit, plastisite indisi, optimum su muhtevası ve şişme basıncının azaldığı, plastik limit, kuru birim hacim ağırlığın ve serbest basınç direncinin arttığı görülmüştür. Pomza-kil ikili karışımları için ideal pomza karışım oranı $\% 20$, pomza-kil-kireç üçlü karışımlarında ise serbest basınç mukavemeti açısından ideal oran $\% 25$ olarak belirlenmiştir.

Bitlis pomzasının kile ilave edilmesi ile pomza-kil ikili karışımlarında pomza oranının artması ile likit limit, plastik limit, plastisite indisi, optimum su muhtevası ve şişme basıncının azaldığı, maksimum kuru birim hacim ağırlığın ve serbest basınç direncinin arttığı görülmüştür, Pomza-kil-kireç üçlü karışımlarında pomza oranının artması ile likit limit, plastisite indisi, optimum su muhtevası ve şişme basıncının azaldığı, plastik limit, kuru birim hacim ağırlığın ve serbest basınç direncinin arttığı görülmüştür. Pomza-kil ikili karışımları için ideal pomza karışım oranı \%20, pomza-kil-kireç üçlü karışımlarında ise serbest basınç mukavemeti açısından ideal oran \%10 olarak belirlenmiştir.

Pomza-kil-kireç üçlü karışımlarında, Manisa Kula pomzası ve Bitlis pomzasının kireç ile tepkimeye girdiği gözlemlenirken, Isparta Gelincik pomzasının kireç ile iyi bir tepkimeye girmediği gözlemlenmiştir.

Pomza-kil ikili karışımlarda ideal pomza oranları Isparta Gelincik, Manisa Kula ve Bitlis pomzaları için sırasıyla \%30, \%20, \%20 olarak belirlenmiş ve bu oranın Isparta Gelincik pomzası için daha yüksek olduğu, Manisa Kula ve Bitlis pomzaları için ise ideal oranlarının eşit olduğu gözlemlenmiştir. Pomza-kil-kireç üçlü karışımlarında ise Isparta Gelincik pomzası için ideal oranın olmadığı, Manisa Kula pomzası için \%25 ve Bitlis pomzası için \%10 olduğu ve ideal oranın Manisa Kula pomzası için daha yüksek olduğu gözlemlenmiştir.

Çalışmanın farklı katkı malzemeleri ile çeşitlendirilip ileri araştırmalarla daha detaylı deneyler yapılarak geliştirilmesi düşünülmektedir.

\section{Yazarların Katkısı}

Çalışmada tüm yazarlar eşit oranda katkı sunmuştur.

\section{Çıkar Çatışması Beyanı}

Yazarlar arasında herhangi bir çıkar çatışması bulunmamaktadır.

\section{Araştırma ve Yayın Etiği Beyanı}

Yapılan çalışmada, araştırma ve yayın etiğine uyulmuştur.

\section{Kaynaklar}

[1] Cömert A.T. 2005. Uçucu Küllerin Zemin Stabilizasyona Etkileri. Yüksek Lisan Tezi, Sakarya Üniversitesi, Fen Bilimleri Enstitüsü, 43s, Sakarya.

[2] Çakılcıoğlu İ. 2007. Yüksek Plastisiteli Killerin Stabilizasyonu, Yüksek Lisans Tezi, Sakarya Üniversitesi, Fen Bilimleri Enstitüsü, 84s, Sakarya.

[3] Önalp A. 2002. Geoteknik Bilgisi 1 Çözümlü Problemlerle Zeminler Ve Mekaniği. Birsen Yayınevi, 408s, İstanbul.

[4] Karthik S., Ashok Kumar E., Gowtham P., Elango G., Gokul D., Thangaraj S. 2014. Soil Stabilization By Using Fly Ash. IOSR Makine ve İnşaat Mühendisliği Dergisi, 10 (6): 20-26.

[5] Taş M., Fidan D., Yılmaz F. 2018. Uçucu Kül ve Bayburt Taş1 ile Zemin Stabilizasyonu, Bayburt Üniversitesi Fen Bilimleri Dergisi, 1(1): 8-14.

[6] Gündüz L. 1998. Pomza Teknolojisi Cilt 1. Süleyman Demirel Üniversitesi Yayınevi, 285s, Isparta. 
[7] Efe T. 2011. Edremit Travertenleri ve Van Gölü Kuzeyinde Yüzeylenen Pomzaların Çimento Sektöründe Kullanılabilirliğinin Araştırılması. Yüksek lisans Tezi, Yüzüncü Y1l Üniversitesi, Fen Bilimleri Enstitüsü, 175s, Van.

[8] Kalay E. 2010. Sıkıştırılmış Yüksek Plastisiteli Kil Zemin Stabilizasyonunda Pomza, Mermer Tozu Ve Kirecin Kullanılması. Yüksek Lisans Tezi, Süleyman Demirel Üniversitesi Fen Bilimleri Enstitüsü, 54s, Isparta.

[9] Coşan F.Ş. 2016. Amorf Silika, Volkanik Tüf Ve Kireç Kullanılarak İyileştirilmiş Yüksek Plastisiteli Kilin Mühendislik Özellikleri. Yüksek Lisans Tezi, Süleyman Demirel Üniversitesi, Fen Bilimleri Enstitüsü, 118s, Isparta.

[10] Taşkın V. 2016. Bitlis Pomzası İle Kendiliğinden Yerleşen Hafif Beton Tasarımı Ve Özeliklerinin Araştırılması Yüksek Lisans Tezi, Bitlis Eren Üniversitesi, Fen Bilimleri Enstitüsü, 113s, Bitlis.

[11] ASTM D 4318-05, 2010. Standard Test Methods for Liquid Limit, Plastic Limit, and Plasticity Index of Soils. ASTM, USA.

[12] ASTM D 698-07 E1, 2009. Standard Test Methods for Laboratory Compaction Characteristics of Soil Using Standard Effort. ASTM, USA.

[13] ASTM D2166 / D2166M-13, 2013. Standard Test Method for Unconfined Compressive Strength of CohesiveSoil, ASTM International, USA.

[14] ASTM D 4546-90, 1993. Standard Test Method for One-Dimensional Swell or Settlement Percent of Cohesive Soils. ASTM, USA. 